\title{
Predicting the 2000-m Rowing Ergometer Performance from Anthropometric, Maximal Oxygen Uptake and 60-s Mean Power Variables in National Level Young Rowers
}

\author{
by \\ Dario Cerasola ${ }^{1}$, Marianna Bellafiore ${ }^{1}$, Angelo Cataldo ${ }^{1}$, Daniele Zangla1, \\ Antonino Bianco ${ }^{1}$, Patrizia Proia ${ }^{1}$, Marcello Traina ${ }^{1}$, Antonio Palma ${ }^{1}$, \\ Laura Capranica ${ }^{2}$
}

\begin{abstract}
Many studies reported various relationships between 2000-m rowing performance and anthropometric as well as metabolic variables, however, little is known about 60-s mean power in elite youth athletes. The aim of this study was to develop different regression models to predict 2000-m rowing indoor performance time ( $\left.t_{2000}\right)$ using anthropometric variables, maximal oxygen uptake $\left(V_{2}\right.$ max $)$ and mean power established during a 60 -s all-out test $\left(W_{60}\right)$ in national elite youth rowers. Fifteen youth male Italian rowers (age: $15.7 \pm 2.0$ years; body height: $176.0 \pm 8.0 \mathrm{~cm}$; body mass: $71.2 \pm$ $10.0 \mathrm{~kg}$ ) performed an incremental maximal test, a 60-s all-out test and a 2000-m race simulation using a Concept2 rowing ergometer to assess $V_{2} O_{2 m a x}, W_{60}$ and $t_{2000}$, respectively. The relationships of all variables with t2000 were investigated through Pearson's correlation. Multiple regression analyses were used to verify the best prediction model of 2000-m indoor rowing performance. The reliability of these models was expressed by $R^{2}$ and the standard error of estimate. The results showed that $t 2000$ was significantly correlated with all the examined variables, except for $V_{2} O_{2 m a x} / b o d y$ mass and age, and exhibited the significantly highest relationship with $\mathrm{W}_{60}(r=-0.943)$. The combination of anthropometric, $V_{2} \mathrm{zmax}_{2}$ and $W_{60}$ variables was found to be the most reliable equation to predict t2000 $(R 2=0.94$, SEE $=6.4)$. $W_{60}$ measure should be considered when monitoring the rower's capability to perform high-intensity phases, important during the race's fast start and end. Not requiring expensive equipment and long duration, a 60-s all-out test could be considered a valuable tool for predicting 2000-m performance of elite youth rowers.
\end{abstract}

Key words: elite youth athletes, mean power, indoor rowing, anthropometric variables, $V \mathrm{O}_{2 m a x}$, rowing performance.

\section{Introduction}

Rowing is a distance-based Olympic sport, with international races organized over a 2000-m distance. Depending on the type of the boat, sex and age categories of athletes, rowing performances usually last 5-8 min, heavily relying on the aerobic (65-80\%) and anaerobic (20-35\%) metabolism to cover as fast as possible the race distance (Martin and Tomescu, 2017; Secher, 1993; Smith and Hopkins, 2012). Therefore, to achieve successful on water rowing performance, it is crucial to administer tactically the individual resources throughout the competition in relation to the opponents and the environmental changing conditions (Cerasola et al., 2018; Garland, 2005).

In the literature, several physiological (Ingham et al., 2002; Riechman et al., 2002; Secher, 1983), anthropometric (Bourgois et al., 2000; Jurimae et al., 2000; Mikulić, 2008; Secher, 1993), and psychological aspects (Kellmann and KlausDietrich, 2000) affecting rowing performance have been investigated. In particular, maximal oxygen uptake $\left(\mathrm{VO}_{2 \max }\right)$ and anthropometric characteristics proved to be strongly related to rowing performance (Ingham et al., 2002; IzquierdoGabarren et al., 2010; Nevill et al., 2011), with

1 - Department of Psychology, Educational Science and Human Movement, University of Palermo, Palermo, Italy.

2 - Department of Movement, Human and Health Sciences, University of Rome Foro Italico, Rome, Italy. 
absolute $\mathrm{VO}_{2 \max }$ considered the best predictor in elite rowers (Ingham et al., 2002; Nevill et al., 2011). Although youth rowers' performance is also associated with physiological and anthropometric characteristics (Bourgois et al., 2000; Cataldo et al., 2015; Jurimae et al., 2000; Mikulić and Ruzić, 2008), variations in body composition, somatic growth and proportions can have a direct influence on sport performance (Malina et al., 2004). Therefore, for comparative purposes it could be more appropriate to express physiological variables relatively to the youth athlete's body mass (Cosgrove et al., 1999; Maciejewski et al., 2016; Mikulić, 2008).

In general, peak power produced during $<10$-s maximal exercise is considered an indicator of the phosphogenic energy system capacity, whereas mean power obtained during 20-60-s allout exercises reflects the capacity of phosphogenic and glycolytic energy systems (Serresse et al., 1988). During 2000-m rowing competitions, the main energy systems providing ATP include anaerobic glycolysis and oxidation of glycogen. In particular, the aerobic energy produced by muscle glycogen represents the energy form over an average period of $288.02 \pm 10.2 \mathrm{~s}$ that corresponds to $77.94 \pm 3.39 \%$ of the total energy provided during the race (Martin and Tomescu, 2017). Therefore, to sustain the critical fast spurts of the starting and finishing phases of the race, the anaerobic metabolism plays an important role (Akça, 2014; Cataldo et al., 2015; Ingham et al., 2002; Izquierdo-Gabarren et al., 2010). In order to assess the athletes' anaerobic power, all-out 20-s and 30-s indoor rowing tests are used (Akça, 2014; Cataldo et al., 2015; Riechman et al., 2012), however, this evaluation may not reflect initial spurts and final sprints that last about $60 \mathrm{~s}$, with an estimated energy expenditure of 700-1200 Watt (Hartmann, 1993; Lawton, 2013; Steinacker, 1993). Therefore, a 60-s maximal rowing ergometer test could be more suitable for the monitoring of the rowers' capability to sustain the energy expenditure during the actual start and finish phases of a race. Furthermore, there is a need to determine the best variables predicting 2000-m performance of youth rowers to help coaches plan their training programmes.

Thus, the aim of the present study was to develop different regression models to predict 2000-m rowing indoor performance time (t2000) using as variables the anthropometric characteristics, $\mathrm{VO}_{2 \max }$, 60-s mean power (W60) in national elite youth rowers. We hypothesized that the combination of these variables could produce the best multiple regression model for a 2000-m rowing indoor performance of national elite youth rowers.

\section{Methods}

\section{Participants}

Eight national champions and seven finalists of the Italian Men's Rowing Junior (15-18 years) Championship (age: $15.7 \pm 2.0$ years; body height $176.0 \pm 8.0 \mathrm{~cm}$; body mass $71.2 \pm 10.0 \mathrm{~kg}$ ) volunteered for this study. Although competing for various clubs, athletes trained according to the Italian Rowing Federation programme encompassing 7 training sessions per week with a total volume of 15 hours. Athletes had at least 3year competitive rowing experience at the national level. Written informed consent for participation was obtained from athletes and their parents, following an explanation on the nature and the purpose of the study. The procedures were conducted in compliance with the Declaration of Helsinki and received the IRB Committee approval.

\section{Design and Procedures}

In the afternoons of three consecutive days, athletes performed indoor tests on a rowing ergometer (Concept2, Mod. D, Morisville, USA) preceded by a standard 15-min rowing warm-up with a 120-drag factor. Before starting the testing procedure, the athletes' stature and mass were evaluated with a stadiometer and an electronic balance (SECA, Germany), respectively. On the first day, athletes performed an incremental maximal test to determine $\mathrm{VO}_{2 \max }$ (Cosgrove et al., 1999). The test encompassed a progressive increase in speed, starting from a 2:30 min:s $500-\mathrm{m}$ split time, with subsequent 5 -s split time decreases every minute until the participant reached volitional exhaustion. Average ventilation, oxygen uptake $\left(\mathrm{VO}_{2}\right)$, and carbon dioxide production $\left(\mathrm{VCO}_{2}\right)$ were recorded every $30 \mathrm{~s}$ by means of a telemetric open-circuit measurement system (K2 Cosmed, Rome, Italy), calibrated with a 3-1 syringe and known $\mathrm{O}_{2}$ gas mixtures $\left(16 \%\right.$ and $20.9 \% \mathrm{O}_{2}$ ). The average heart rate (HR) was monitored every $5 \mathrm{~s}$ by means of a heart rate monitor (Sport Tester, Polar Electro, Kempele, Finland). The occurrence 
of $\mathrm{VO}_{2 \max }$ was identified by: 1) a plateau or an increase $<1 \mathrm{ml} \cdot \mathrm{kg}^{-1} \cdot \mathrm{min}^{-1}$ of oxygen uptake despite further increases in the exercise intensity; and 2) HR reached 10 beat $\mathrm{min}^{-1}$ of the predicted HRmax (220 - age). On the second day, rowers completed a 60 -s all-out test with verbal encouragement. The power output of every stroke measured in Watt (W) was assessed with a computer integrated (Concept PM3) to the ergometer, which provided the mean power recorded during $60 \mathrm{~s}$ of a maximal rowing ergometer test $\left(\mathrm{W}_{60}\right)$. On the third day, rowers performed a 2000-m trial at their best and the time $\left(\mathrm{t}_{2000}\right)$ was recorded.

\section{Statistical analyses}

Data were analysed (SPSS 23, Chicago, IL, USA) with a level of confidence of 0.05 and reported as means \pm standard deviations. Absolute $\mathrm{W}_{60}$ and $\mathrm{VO}_{2 \max }$ data were also normalized relatively to the athlete's body mass. Pearson correlation coefficients $(r)$, coefficients of determination $\left(R^{2}\right)$, and $95 \%$ confidence intervals ( $95 \%$ C.I.) were used to determine the association between rowing performance ( $\left.\mathrm{t}_{2000}\right)$, anthropometric, absolute and normalized $\mathrm{W}_{60}$ and

$\mathrm{VO}_{2 \max }$ variables. Multiple regression analyses were applied to verify the best prediction model of a 2000-m indoor rowing performance. For all equations, the variables that resulted in the lowest possible standard error of estimate (SEE) were used. Reliability of the regression models was expressed by $\mathrm{R}^{2}$ and SEE.

\section{Results}

Absolute $\mathrm{W}_{60}$ and $\mathrm{VO}_{2 \max }$ were $476.1 \pm 91.0 \mathrm{~W}$ and $4669.0 \pm 842.0 \mathrm{ml} \cdot \mathrm{min}^{-1}$, respectively. The relative picture for normalized data was $6.63 \pm 0.6$ $\mathrm{W} \cdot \mathrm{kg}^{-1}$ and $65.8 \pm 8.7 \mathrm{ml} \cdot \mathrm{min}^{-1} \cdot \mathrm{kg}^{-1}$, respectively. The time of $2000-\mathrm{m}$ performance on the rowing ergometer was $417.1 \pm 21.8 \mathrm{~s}$. As shown in Table 1, t2000 negatively correlated with all the examined variables and showed the highest significant relationship with absolute $\mathrm{W}_{60}(\mathrm{r}=-0.943)$. Conversely, no significant relationship emerged for normalized $\mathrm{VO}_{2 \max }$ and age of the athletes (Table 1). As reported in Table 2, prediction models of 2000-m rowing indoor performance showed the highest $\mathrm{R}^{2}$ value (0.94) and variance $(92 \%)$, and the lowest SEE (6.4) for the equation combining all the studied variables.

\begin{tabular}{|c|c|c|c|c|c|c|c|}
\hline \multicolumn{8}{|c|}{$\begin{array}{c}\text { Table } \\
\left.\text { Correlation between 2000- } m \text { rowing ergometer performance ( } t_{2000}\right) \\
\text { and anthropometric, } W_{60} \text { and } V_{2 m a x} \text { variables. }\end{array}$} \\
\hline & $\begin{array}{l}\text { Age } \\
(\mathrm{yr})\end{array}$ & $\begin{array}{l}\text { Height } \\
(\mathrm{cm})\end{array}$ & $\begin{array}{l}\text { Body mass } \\
\quad(\mathrm{kg})\end{array}$ & $\begin{array}{l}W_{60} \\
(W)\end{array}$ & $\begin{array}{l}\text { W60/body weight } \\
\left(\mathrm{W} \cdot \mathrm{kg}^{-1}\right)\end{array}$ & $\begin{array}{l}\mathrm{VO}_{2 \max } \\
\left(\mathrm{ml} \cdot \mathrm{min}^{-1}\right)\end{array}$ & $\begin{array}{c}\mathrm{VO}_{2 \max } / \text { body mass } \\
\left(\mathrm{ml} \cdot \mathrm{kg}^{-1} \cdot \mathrm{min}^{-1}\right)\end{array}$ \\
\hline$r$ & -0.488 & -0.877 & -0.815 & -0.943 & -0.699 & -0.761 & -0.475 \\
\hline$R^{2}$ & 0.238 & 0.769 & 0.665 & 0.889 & 0.489 & 0.579 & 0.226 \\
\hline$P$ & 0.051 & $<0.0001$ & $<0.0001$ & $<0.0001$ & $<0.05$ & $<0.0001$ & 0.49 \\
\hline C.I. & $-0.80 ; 0.03$ & $-0.96 ;-0.66$ & $-0.94 ;-0.52$ & $-0.98 ;-0.83$ & $-0.89 ;-0.29$ & $-0.92 ;-0.41$ & $-0.79 ; 0.05$ \\
\hline & & $\begin{array}{l}\text { arson corre } \\
\text { P: level of }\end{array}$ & $\begin{array}{l}\text { lation coeff } \\
\text { confidence; }\end{array}$ & $\begin{array}{l}\text { icient; } R^{2}: c \\
95 \% \text { C.I.: } s\end{array}$ & $\begin{array}{l}\text { efficient of detern } \\
5 \% \text { confidence in }\end{array}$ & $\begin{array}{l}\text { mination; } \\
\text { iterval }\end{array}$ & \\
\hline
\end{tabular}




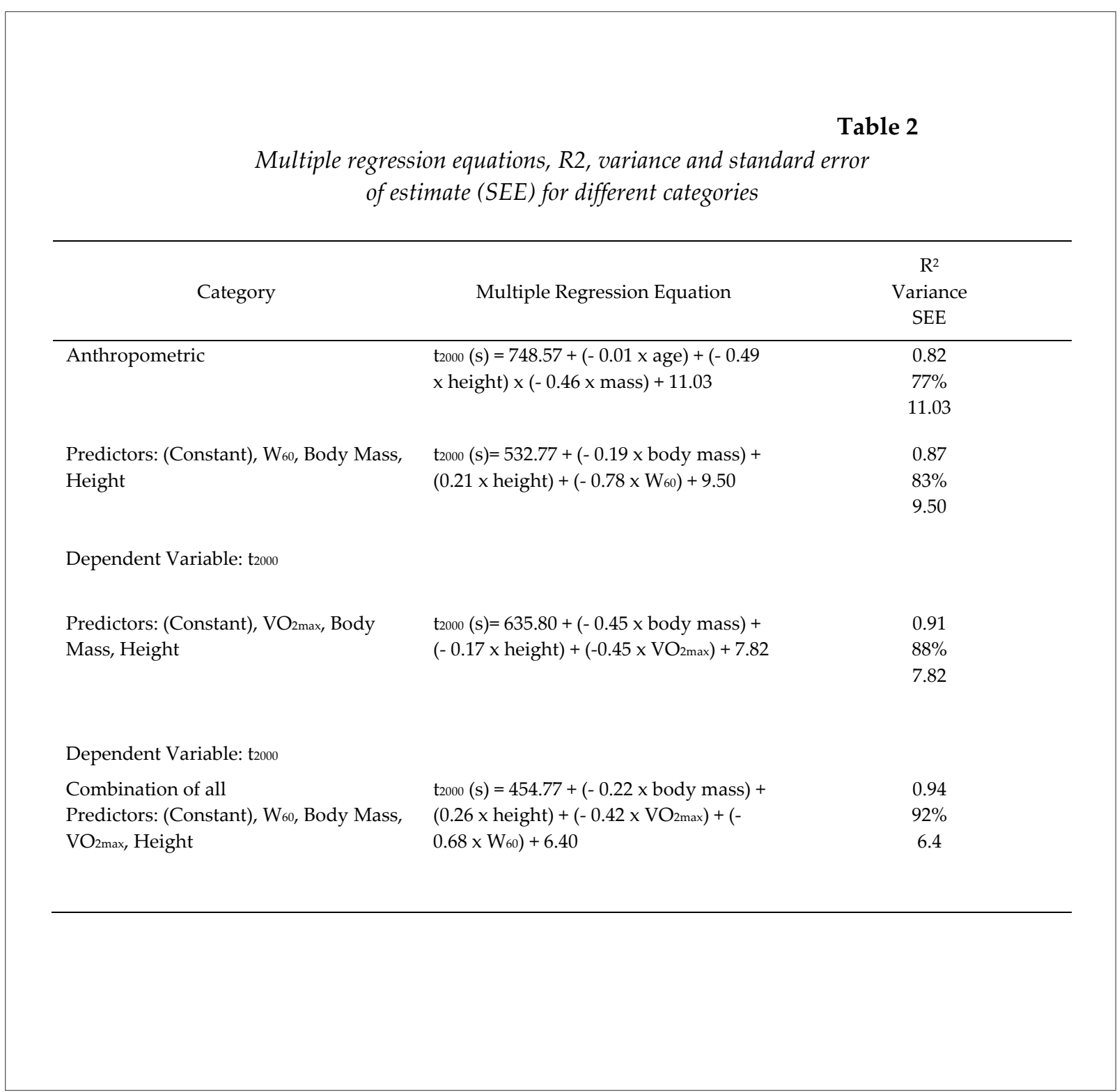

\section{Discussion}

The main findings of the present study support the relationship between body mass, height, $\mathrm{VO}_{2 \max }$, and $\mathrm{W} 60$ variables with respect to t2000 indoor rowing performance. Furthermore, the studied variables could be useful for predicting elite youth rowing performance. Conversely, age per se seems not to be a determinant for success of the best athletes of this junior category, whereas it could be a relevant factor at lower competitive levels where the athlete's training and competition experience are at stake.

In line with the literature, body height and mass highly correlated with t2000 (Akça, 2014; Dimakopoulouet al., 2007; Maciejewski et al., 2016;
Slater et al., 2005). In fact, anthropometric variables showed high prediction of 2000-m ergometer rowing performance $(\mathrm{R} 2=0.82)$, comparable to that reported for college level athletes (Akça, 2014) and higher than those of previous studies ( $\mathrm{R} 2$ range: 0.76-0.78) on youth rowers of a lower athletic level (Jurimae et al., 2000; Russell et al., 1998). Also, $\mathrm{VO}_{2 m a x}$ exhibited a high correlation and prediction capacity with t2000 as previously reported in other studies (Cosgrove et al., 1999; Ingham et al., 2002; Yoshiga et al., 2000). Despite the present data confirmed the relevance of the metabolic variables in rowing performance (Akça, 2014; Cosgrove et al., 1999; Riechman et al., 2002; Russell et al., 1998), when body mass was used to normalize $\mathrm{VO}_{2 \max }$, no correlation to $\mathrm{t} 2000$ was found. In this regard, 
controversial results are present in the literature (Cosgrove et al., 1999; Nevill et al., 1992; Secher, 1983) and the explanation could be that body mass in rowers does not put them at the same disadvantage that it would put athletes who carry their own body mass (i.e. running, jumping, etc.). However, many studies concur that a strong relationship exists between 2000-m rowing performance and $\mathrm{VO}_{2 \max }$ normalized to lean body mass (Cosgrove et al., 1999; Mikulic, 2008; Slater et $\mathrm{al}, 2005)$. The lack of correlation between $\mathrm{t} 2000$ and $\mathrm{VO}_{2 \max } /$ body mass could be also due to the selection process of national level junior athletes participating in our study, that favoured experienced, taller and heavier rowers with respect to their less successful counterparts (Bourgois et al., 2000; Kaloupsis et al., 2008, Mikulic, 2008). Therefore, our findings do not sustain the use of normalized $\mathrm{VO}_{2 \max }$ in monitoring performance of elite youth rowers.

Other factors such as muscle fiber type composition, neural factors, technical aspects, competition experience and effort management could be more relevant in predicting 2000-m youth rowing performance (Akça, 2014; Brown et al., 2010; Cataldo et al., 2015; Dimakopoulou et al., 2007; Garland et al., 2005), also substantiated by the good prediction capacity of the metabolic variables. In particular, the previous knowledge on the role of $\mathrm{VO}_{2 \max }$ (Ingham et al., 2002; Riechman et al., 2002; Russell et al., 1998) has been implemented with that of the W60 variable.

To date, various studies have reported a positive correlation between 2000-m indoor rowing performance and power output produced during $20 \mathrm{~s}, 30 \mathrm{~s}$ and $40 \mathrm{~s}$ all-out rowing tests (Cataldo et al., 2015; Jurimae et al, 2000; Maciejewski et al., 2016). Considering the duration and typology of these tests, it is possible to hypothesize that the mean power was supported mainly by the ATP-CP and glycolytic contributions.

In our study, we found a high correlation between t2000 and power output produced during the 60-s maximal rowing test and adopted this test because the produced mean power could better reflect the initial and final stages of the race as described by Steinacker et al. (1993). Moreover, Carey and Richardson (2003) supported that in a 60 -s maximal cycling test athletes achieved $92 \%$ of $\mathrm{VO}_{2 \max }$ compared with an incremental $\mathrm{VO}_{2 \max }$ test showing a relevant contribution of the aerobic metabolism. Therefore, the W60 variable could be considered when monitoring the rower's capability to perform high-intensity prolonged phases in the race. Differently to the 20-s maximal ergometer test, the 60-s all-out test could be more suitable for assessing well-trained youth rowers as it mostly reflects the aerobic determinant contributing to 2000-m competition in elite rowers (Martin and Tumescu, 2017; Mikulic, 2008; Secher, 1993). Indeed, in our study rowers' $\mathrm{VO}_{2 \max }$ data were similar to those of Croatian elite junior rowers (65.8 8.7 vs. $62.5 \pm 4.7 \mathrm{ml}$ min- $1 \mathrm{~kg}-1$, respectively) indicating high values of aerobic capacity (Mikulic, 2008). Moreover, seniors have higher $\mathrm{VO}_{2 \max }$ values than juniors due to increased body mass and long hours of rowing specific training that results in a greater aerobic capacity. Whether a male rower expects to achieve success at the international level, it will be necessary to produce maximal oxygen uptake that approaches 6.0 L/min (Mikulic, 2008; Secher, 1993).

We also detected that the best prediction model for 2000-m indoor performance in elite youth rowers involved the combination of anthropometric, $\mathrm{VO}_{2 \max }$ and $\mathrm{W} 60$ variables suggesting that monitoring of these elements is crucial for planning the training protocol and optimizing performance. However, also W60 has a high capacity of performance prediction that is almost equal to the combination of all the variables examined. Thus, considering that $\mathrm{VO}_{2 \max }$ measure requires expensive equipment, specific scientific expertise and long duration, the measurement of W60 could be easily used by coaches for talent identification because indoor rowing performance is a good predictor of on-water 2000-m time with a standard error of the estimate ranging between 2.6 and 7.2\% (Smith and Hopkins, 2012).

This study offers insights into anthropometrical and physiological aspects related to the elite youth rowing performance. This information is fundamental for providing a series of useful indications to assist coaches in the optimization of the evaluation, monitoring and prediction of rowing performance of youth athletes. In particular, coaches are advised to make use of all-out rowing tests, which could mirror the most intensive phases of the competition to attain the fastest rowing velocities in the initial and last part of the race, which could allow achieving the 
best possible finishing positions. The predictive values of the variables presented in this study can be also seen as an important addition to the talent identification purposes in rowing.

This conclusion is limited to this particular sample of finalists and medallists in the Italian
Men's Rowing Junior Championship. Further studies are needed to verify whether this test is useful for monitoring individual rowers of different levels, age and sex.

\section{Acknowledgements}

The authors wish to thank directors and athletes of Canottieri Telimar and Club Lauria for their kind collaboration in this study.

\section{References}

Akça F. Prediction of rowing ergometer performance from functional anaerobic power, strength and anthropometric components. J Hum Kinet, 2014; 41: 133-142

Bourgois J, Claessens AL, Vrijens J, Philippaerts R, Van Renterghem, B, Thomis M, Janssens M, Loos R, Lefevre J. Anthropometric characteristics of elite male junior rowers. Br J Sports Med, 2000; 34: 213-216

Brown MR, Delau S, Desgorces FD. Effort regulation in rowing races depends on performance level and exercise mode. J Sci Med Sport, 2010; 13(6): 613-617

Carey DG, Richardson MT. Can aerobic and anaerobic power be measured in a 60-second maximal test? J Sports Sci Med, 2003; 2(4): 151-7

Cataldo A, Cerasola D, Russo G, Zangla D, Traina M. Mean power during $20 \mathrm{sec}$ all-out test to predict $2000 \mathrm{~m}$ rowing ergometer performance in national level young rowers. J Sports Med Phys Fitness, 2015; 55(9): $872-877$

Cerasola D, Cataldo A, Bellafiore M, Traina M, Palma A, Bianco A, Capranica L. Race profiles of rowers during the 2014 Youth Olympic Games. J Strength Cond Res, 2018; 32(7): 2055-2060

Cosgrove MJ, Wilson J, Watt D, Grant SF. The relationship between selected physiological variables of rowers and rowing performance as determined by a 2000-m ergometer test. J Sports Sci, 1999; 17(11): 845-852

Dimakopoulou E, Blazevich AJ, Kaloupsis S, Diafas V, Bachev V. Prediction of stroking characteristics of elite rowers from anthropometrics variables. Serbian J Sport Sci, 2007; 1: 91-97

Garland SW. An analysis of the pacing strategy adopted by elite competitors in $2000 \mathrm{~m}$ rowing. Br J Sports Med, 2005; 39: 39-42

Hartmann U, Mader A, Wasser K, Klauer I. Peak force, velocity, and power during five and ten maximal rowing ergometer strokes by world class female and male rowers. Int J Sports Med, 1993; 14 Suppl 1: S42-5

Ingham SA, Whyte GP, Jones K, Nevill AM. Determinants of 2000-m rowing ergometer performance in elite rowers. Eur J Appl Physiol, 2002; 88(3): 243-246

Izquierdo-Gabarren M, Gonzàlez DE, Txabarri Expòsito R, Sàez Sàez de Villarreal E, Izquierdo M. Physiological factors to predict on traditional rowing performance. Eur J Appl Physiol, 2010; 108(1): 8392

Jurimae J, Maestu J, Jurimae T, Pihl E. Prediction of rowing performance on single sculls from metabolic and anthropometric variables. J Hum Movement Stud, 2000; 38: 123-136

Kaloupsis S, Bogdanis GC, Dimakopoulou E, Maridaki M. Anthropometric characteristics and somatotype of young Greek rowers. Bio Sport, 2008; 25(1): 57

Kellmann M, Klaus-Dietrich G. Changes in stress and recovery in elite rowers during preparation for the Olympic Games. Med Sci Sports Exerc, 2000; 32(3): 676-683 
Lawton TW, Cronin JB, McGuigan MR. Strength, power, and muscular endurance exercise and elite rowing ergometer performance. J Strength Cond Res, 2013; 27(7): 1928-35

Maciejewski H, Rahmani A, Chorin F, Lardy J, Giroux C, Ratel S. The 1,500-m rowing performance is highly dependent on modified Wingate anaerobic test performance in national-level adolescent rowers. Pediatr Exerc Sci, 2016; 28(4): 572-579

Malina R, Bouchard C, Bar-Or O. Growth, Maturation, and Physical Activity (2nd Ed.). Champaign: Human Kinetics Publ; 2004

Martin SA, Tomescu V. Energy system efficiency influences the results of 2,000 $\mathrm{m}$ race simulation among elite rowers. Clujul Medical, 2017; 90: 60-65

Mikulić P. Anthropometric and physiological profiles of rowers of varying ages and ranks. Kinesiology, 2008; 40(1): 80-88

Mikulić P, Ruzić L. Predicting the 1000m rowing ergometer performance in 12-13-year-old rowers: the basis for selection process? J Sci Med Sport, 2008; 11(2): 218-226

Nevill AM, Allen SV, Ingham AM. Moddelling the determinants of 2000-m rowing ergometer performance: a proportional, curvilinear allometric approach. Scand J Med Sci Spor, 2011; 21(1): 73-78

Riechman SE, Zoeller RF, Balasekaran G, Goss FL, Robertson RJ. Prediction of $2000 \mathrm{~m}$ indoor rowing performance using a $30 \mathrm{~s}$ sprint and maximal oxygen uptake. J Sports Sci, 2002; 20(9): 681-687

Russell AP, Le Rossignol PF, Sparrow WA. Prediction of elite schoolboy 2000m rowing ergometer performance from metabolic, anthropometric and strength variables. J Sports Sci, 1998; 16(8): 749-754

Secher NH. The physiology of rowing. J Sports Sci, 1983; 1(1): 23-53

Secher NH. Physiological and biomechanical aspects of rowing. Implications for training. Sports Med, 1993; 15(1): 24-42

Serresse O, Lortie G, Bouchard C, Boulay MR. Estimation of the contribution of the various energy systems during maximal work of short duration. Int J Sports Med, 1988; 9: 456-60

Slater GJ, Rice AJ, Mujika I, Hahn AG, Sharpe K, Jenkins DG. Physique traits of lightweight rowers and their relationship to competitive success. Br J Sports Med, 2005; 39: 736-741

Smith TB, Hopkins WG. Measures of rowing performance. Sports Med, 2012; 42(4): 343-358

Steinacker JM. Physiological aspect of training in rowing. Int J Sports Med, 1993; 14Suppl 1: s3-s10

Yoshiga, CC, Kawakami Y, Fukunaga T, Okamura K, Higuchi M. Anthropometric and physiological factors predicting $2000 \mathrm{~m}$ rowing ergometer performance time. Advances in Exercise and Sports Physiology, 2000; 6: $51-57$

\section{Corresponding author:}

\section{Marianna Bellafiore}

Giovanni Pascoli 6

90100 Palermo

Italy

Phone: +39-091-23896909

E-mail: marianna.bellafiore@unipa.it 